\title{
Measurement of exhaled nitric oxide in man
}

\author{
Colin Borland, Yolande Cox, Tim Higenbottam
}

\begin{abstract}
Background-Nitric oxide is released from pulmonary endothelial cells and contributes to the low pulmonary vascular resistance. The resistance pulmonary arteries are in close anatomical proximity to membranous airways, so it is likely that some pulmonary endothelial nitric oxide will enter the airspace to allow its measurement in the exhaled breath.

Methods-Exhaled air was collected from a single full exhalation and during tidal breathing. This was analysed for concentrations of nitric oxide, nitrogen dioxide, and carbon dioxide to give alveolar (FA) and mixed expired (FE) concentrations. Eight normal subjects were studied and laboratory air was similarly analysed using, respectively, chemiluminescent and infrared analysers.

Results-There was no relation between FA concentrations and the laboratory air concentrations. From the single breath, the ratio of $\left(\mathbf{F A N O} / \mathbf{F A C O}_{2}\right) \times\left(\mathrm{FeCO}_{2}\right)$ Feno) had a mean value of $0.92(95 \%$ confidence interval 0.7 to $1 \cdot 14$ ). As this does not differ from unity, nitric oxide is likely to be derived from the same regions of the lungs as carbon dioxide. During tidal breathing the FENo ranged from $8 \cdot 3$ to $20 \cdot 3$ parts per billion.

Conclusions-It is possible to measure endogenous pulmonary nitric oxide production in the exhaled air in man.
\end{abstract}

(Thorax 1993;48:1160-1162)

Nitric oxide (NO) is a ubiquitous gaseous free radical which acts as an intracellular messenger with a range of regulatory roles in different tissues. ${ }^{1}$ In the endothelium, nitric oxide functions in vascular signalling and is responsible for the activity of endothelium derived relaxing factor. ${ }^{2}$ Released by pulmonary endothelium, nitric oxide contributes to the characteristically low pulmonary vascular resistance. ${ }^{3}$ Hypoxic lung disease may cause a reduction in pulmonary endothelium production. ${ }^{4}$ Inhaled in concentrations of 40 parts per million (ppm), nitric oxide is a powerful selective pulmonary vasodilator. ${ }^{5}$ Implicit in this observation is the idea that gaseous nitric oxide can be exchanged between airspace and smooth muscle cells of resistance pulmonary arteries, which are in close proximity to membranous airways. ${ }^{6}$ It can be questioned whether a similar exchange could occur between the abluminal surface of the pulmonary endothelial cells and the airspace, so allowing measurements of endogenously produced nitric oxide in exhaled air. This study addresses the question of the practical measurement of exhaled nitric oxide in man, the reproducibility of the measurement, and attempts to determine the site of its origin in the lung.

\section{Methods}

Nitric oxide was measured in air using a sensitive chemiluminescent analyser ${ }^{7}$ (Model 42, Thermoelectron, Warrington, UK) which can measure concentrations of one part per billion (ppb). The analyser was calibrated before each study using a mixture of oxide of nitrogen $\left(\mathrm{NO}_{\mathbf{x}}\right)$ free air and a mixture of 130 ppb of nitric oxide in nitrogen (Spectraseal, BOC, London, UK). This gas concentration in turn was certified by the manufacturers and was verified by reference to a national standard (Department of Trade and Industry, Warren Spring Laboratory, Stevenage, UK). The $\mathrm{NO}_{\mathrm{x}}$ free air was produced by passing room air through the ozone generator of the chemiluminescent analyser which converts all $\mathrm{NO}_{x}$ to nitrogen dioxide. This was then passed through soda lime and activated charcoal to remove the nitrogen dioxide and ozone respectively. The chemiluminescent analyser also allows measurement of nitrogen dioxide. It is reduced within the analyser to nitric oxide using a molybdenum converter. The total nitric oxide was then analysed as described above by the chemiluminescent analyser. The carbon dioxide was separately measured with an infrared analyser (Capnograph IV, Gould, Einthoven, Netherlands) which was calibrated with standard gas mixtures (BOC, London, UK).

The study, approved by our local hospital ethics committee, involved eight healthy volunteers (six women) aged 28-58 years. They were non-smokers and had normal lung function; mean (SD) FEV $121 \%$ (24\%) predicted; mean total lung capacity (TLC) $106 \%(17 \%)$ predicted, and gas transfer for carbon monoxide (TLCO) 109\% (13\%) predicted.

The single breath measurement involved a full breath to TLC, then a full exhalation to residual volume $(\mathrm{RV})$. The last litre of air was 8 collected into a PVC bag from which alveolar concentrations $\left(\mathrm{FA}_{\mathrm{A}}\right)$ of nitric oxide, nitrogen dioxide, and carbon dioxide were measured. The mixed expired concentrations $(\mathrm{FE})$ were also measured from air collected through the full exhalation. All subjects undertook three measurements of each without holding breath 
at TLC. Three subjects separately performed the single breath measurement but held their breath at TLC for $60 \mathrm{~s}$. Again three replicates were performed.

The tidal breathing measurements involved five minutes of spontaneous breathing at rest through a two way Otis-McKerrow valve during which time the exhaled air was collected in a 401 Douglas bag. The FE of nitric oxide, nitrogen dioxide and carbon dioxide were measured. Three repeated measurements were undertaken by all the subjects. The tidal volume (VT) and frequency of breathing ( $f$ ) were recorded from the expiratory part of the two way valve with a Fleisch pneumotachograph, differential pressure transducer and integrator (PK Morgan Ltd, Chatham, Kent, UK). This was calibrated before each measurement with 11 and 31 syringes.

The laboratory air was sampled each time a study was undertaken to estimate environmental concentrations of nitric oxide and nitrogen dioxide.

\section{Results}

In our subjects the FENO in a single breath test ranged from 3.0 to $12.3 \mathrm{ppb}$, while during tidal breathing the range was 8.3 to $20.3 \mathrm{ppb}$ (table). The standard deviations of these measurements in each subject ranged from 0.6 to $5 \cdot 1 \mathrm{ppb}$ and were smaller for the tidal breathing estimates than from a single breath test.

The single breath measurements allow calculation for each subject of the ratio $\left(\mathrm{FANO} / \mathrm{FACO}_{2}\right) \times\left(\mathrm{FECO}_{2} / \mathrm{FENO}\right)$. The mean value of this ratio was 0.92 (95\% confidence interval $0 \cdot 7$ to $1 \cdot 14$ ). As it did not differ from unity, nitric oxide is likely to be derived from similar regions of the lung as carbon dioxide. In this approach no account is taken of atmospheric nitric oxide contaminating inspired gas. Since no gas exchange of nitric oxide occurs in the conducting airways, as we have previously reported, ${ }^{8}$ the nitric oxide concentration of deadspace gas will equal atmospheric:

$$
\frac{F_{E N O}}{F_{A N O}}=\frac{V A}{V A+V D}+\left(\frac{V D}{V_{A}+V_{D}} \times \frac{\text { FINO }}{F_{A N O}}\right)
$$

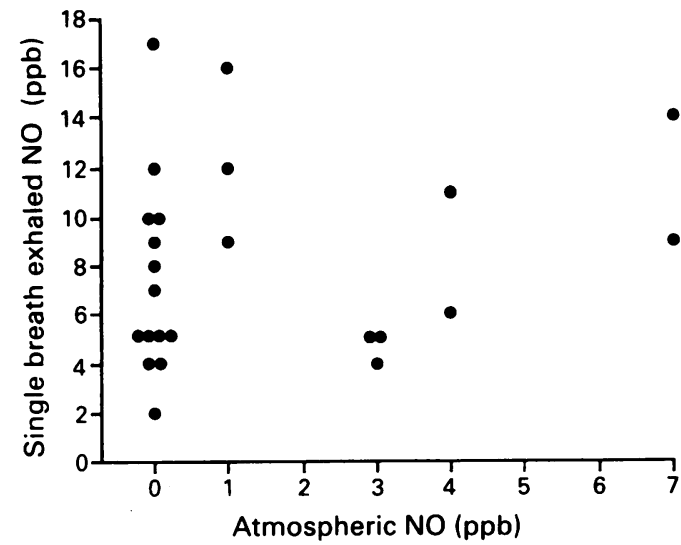

No relation could be found between the alveolar gas concentration of nitric oxide (NO) obtained from a single breath test measured three times by eight subjects and the atmospheric concentration of nitric oxide.

where VA is alveolar volume, $V D$ is dead space volume, and FINO is the atmospheric concentration of nitric oxide. In many instances, however, atmospheric nitric oxide was zero, and when we calculated

$$
\frac{V D}{V A+V D} \times \frac{\text { FINO }}{\text { FANO }}
$$

in no subject was the value equal to or greater than $0 \cdot 05$. For this reason we ignored the inspired nitric oxide in these calculations.

The mean (SD) environmental concentration of nitric oxide was $1 \cdot 4(2 \cdot 2) \mathrm{ppb}$ and of nitrogen dioxide was $7 \cdot 3(5 \cdot 2)$ ppb. The mean $\mathrm{FENO}_{2}$ during spontaneous tidal breathing was lower $(5.5(1.6) \mathrm{ppb})$ than environmental nitrogen dioxide, indicating that environmental nitrogen dioxide was taken up by the lungs. By contrast there was no relationship between environmental concentrations of nitric oxide and the FANO from a single breath test (fig), and exhaled nitric oxide exceeded the environmental concentration.

The single breath FANO in three subjects was $8 \cdot 2(2 \cdot 9) \mathrm{ppb}$ when performed without a breath hold at TLC, and 6.4 (2.9) ppb $(\mathrm{p}<0.05)$ with a breath hold at TLC of $60 \mathrm{~s}$.

The molar rate of production of exhaled nitric oxide (MNO) during tidal breathing was calculated by multiplying FENO minus atmos-

Mean (SD) single breath and tidal breathing exhaled gas concentrations for nitric oxide (NO) and carbon dioxide $\left(\mathrm{CO}_{2}\right)$. Alveolar $\left(\mathrm{F}_{A}\right)$ and mixed expired. $(\mathrm{FE})$ concentrations are shown for both $\mathrm{NO}$ and $\mathrm{CO}_{2}$. The molar rate of output

\begin{tabular}{|c|c|c|c|c|c|c|c|}
\hline \multirow[b]{2}{*}{ Subject } & \multicolumn{4}{|c|}{ Single full exhalation } & \multicolumn{3}{|c|}{ Spontaneous breathing } \\
\hline & $\begin{array}{l}\text { FANO } \\
\left(\times 10^{-9}\right)\end{array}$ & $\begin{array}{l}F_{A C O_{2}} \\
\left(\times 10^{-2}\right)\end{array}$ & $\begin{array}{l}\text { FENO } \\
\left(\times 10^{-9}\right)\end{array}$ & $\begin{array}{l}\mathrm{FECO}_{2} \\
\left(\times 10^{-2}\right)\end{array}$ & $\begin{array}{l}\text { Minute } \\
\text { ventilation } \\
\text { (l/min) }\end{array}$ & $\begin{array}{l}\text { FENO } \\
\left(\times 10^{-9}\right)\end{array}$ & $\begin{array}{l}\dot{M}{ }_{N O} \\
\left(10^{-9} \mathrm{~mol} / \mathrm{min}\right)\end{array}$ \\
\hline $\begin{array}{l}1 \\
2 \\
3 \\
4 \\
5 \\
6 \\
7 \\
7 \\
8\end{array}$ & $\begin{array}{r}4 \cdot 7(0 \cdot 6) \\
9 \cdot 0(1 \cdot 0) \\
14 \cdot 0(2 \cdot 0) \\
4 \cdot 7(0 \cdot 6) \\
11 \cdot 3(5 \cdot 1) \\
6 \cdot 0(4 \cdot 6) \\
6 \cdot 3(2 \cdot 5) \\
8 \cdot 7(3 \cdot 5)\end{array}$ & $\begin{array}{l}3 \cdot 8(0 \cdot 6) \\
5 \cdot 1(0 \cdot 3) \\
5 \cdot 4(0 \cdot 4) \\
4 \cdot 2(0 \cdot 4) \\
5 \cdot 2(0 \cdot 6) \\
4 \cdot 5(0 \cdot 7) \\
5 \cdot 7(1 \cdot 1) \\
4 \cdot 9(0 \cdot 1)\end{array}$ & $\begin{array}{r}4 \cdot 7(0 \cdot 6) \\
5 \cdot 7(1 \cdot 5) \\
12 \cdot 3(2 \cdot 5) \\
3 \cdot 0(1 \cdot 0) \\
7 \cdot 3(1 \cdot 5) \\
6 \cdot 0(1 \cdot 7) \\
8 \cdot 3(2 \cdot 5) \\
5 \cdot 0(1 \cdot 0)\end{array}$ & $\begin{array}{l}3 \cdot 7(0 \cdot 1) \\
3 \cdot 3(0 \cdot 2) \\
3 \cdot 0(0 \cdot 2) \\
3 \cdot 0(0 \cdot 4) \\
3 \cdot 8(0 \cdot 3) \\
3 \cdot 6(0 \cdot 3) \\
3 \cdot 5(0 \cdot 6) \\
3 \cdot 5(0 \cdot 3)\end{array}$ & $\begin{array}{r}12 \cdot 1(1 \cdot 1) \\
8 \cdot 2(4 \cdot 8) \\
8 \cdot 7(2 \cdot 6) \\
11 \cdot 6(2 \cdot 3) \\
9 \cdot 3(0 \cdot 8) \\
8 \cdot 3(0 \cdot 1) \\
8 \cdot 9(0 \cdot 9) \\
7 \cdot 8(0 \cdot 5)\end{array}$ & $\begin{array}{r}8 \cdot 3(1 \cdot 5) \\
17 \cdot 3(4 \cdot 6) \\
14 \cdot 3(0 \cdot 6) \\
11 \cdot 7(2 \cdot 9) \\
13 \cdot 0(4 \cdot 0) \\
20 \cdot 3(2 \cdot 5) \\
15 \cdot 3(2 \cdot 9) \\
17 \cdot 7(1 \cdot 2)\end{array}$ & $\begin{array}{l}3 \cdot 6(0 \cdot 9) \\
5 \cdot 6(4 \cdot 6) \\
4 \cdot 0(1 \cdot 0) \\
4 \cdot 6(1 \cdot 6) \\
5 \cdot 0(1 \cdot 3) \\
6 \cdot 5(0 \cdot 3) \\
5 \cdot 3(1 \cdot 5) \\
5 \cdot 5(0 \cdot 4)\end{array}$ \\
\hline $\begin{array}{l}\text { Mean } \\
\text { SD }\end{array}$ & $\begin{array}{l}8 \cdot 1 \\
3 \cdot 3\end{array}$ & $\begin{array}{l}4 \cdot 9 \\
0 \cdot 6\end{array}$ & $\begin{array}{l}6 \cdot 5 \\
2 \cdot 8\end{array}$ & $\begin{array}{l}3.4 \\
0.3\end{array}$ & $\begin{array}{l}9 \cdot 4 \\
1 \cdot 6\end{array}$ & $\begin{array}{r}14 \cdot 7 \\
3 \cdot 8\end{array}$ & $\begin{array}{l}5 \cdot 0 \\
0.9\end{array}$ \\
\hline
\end{tabular}
of the lungs is shown for tidal breathing (MNO) 
pheric nitric oxide (FINO) by minute ventilation (obtained from VT and $f$ ), and this product was then multiplied by $10^{-9} / 24.04\left(10^{-9}\right.$ converts ppb to fractional concentration and 24.04 converts fractional concentration to molar concentrations at atmospheric temperature and pressure and water saturation). The MNO ranged from 3.6 to $6.5 \times 10^{-9} \mathrm{~mol} / \mathrm{min}$ (table). The standard deviation of these mean values ranged from 0.3 to $4.6 \mathrm{~mol} / \mathrm{min}$.

\section{Discussion}

The concentration of nitric oxide in exhaled air varies in healthy subjects from 8.3 to 20.3 ppb during tidal breathing. From the single breath test, using the fractional alveolar and expired concentrations of nitric oxide and carbon dioxide, it can be predicted that the exhaled nitric oxide was derived from a similar region of the lung as carbon dioxide. An environmental source can be excluded, as the concentration of exhaled nitric oxide exceeded the concentration in laboratory air (fig). This contrasts with exhaled nitrogen dioxide, a gas known to interact with the lungs ${ }^{9}$ but which was shown not to be endogenously produced. The concentration of nitrogen dioxide in exhaled air was lower than environmental nitrogen dioxide. An endogenous source for exhaled nitric oxide was further supported by the experimental finding in guinea pigs and rabbits ${ }^{10}$ that inhibition of the nitric oxide synthase resulted in a fall in exhaled nitric oxide. Studies in isolated lungs perfused with colloid solutions further confirm this finding and suggest that pulmonary endothelium is the source of exhaled nitric oxide. ${ }^{11}$

Cultured endothelial cells are capable of a substantially greater molar rate of production of nitric oxide ${ }^{7}$ than we observed during tidal breathing where the rates ranged from 3.6 to $6.5 \times 10^{-9} \mathrm{~mol} / \mathrm{min}$. However, exhaled nitric oxide will reflect only part of the nitric oxide production by pulmonary endothelial cells. Nitric oxide is the fastest known ligand of haemoglobin ${ }^{12}$ and is rapidly taken up by the lungs when inhaled in concentrations of parts per million, some 4.5 times faster than $0.2 \%$ of carbon monoxide. ${ }^{8}$ It can be assumed that much of the endothelial nitric oxide is taken up by circulating red cells. ${ }^{13}$ Only abluminally produced nitric oxide from the endothelial cells is likely to reach the airspace, and then only that not taken up by vascular smooth muscle cells. A complex dynamic exchange is likely to exist between the blood, the nitric oxide producing pulmonary endothelial cells, and the airspaces. Much remains unclear as to the nature of this dynamic process but breathhold at TLC for $60 \mathrm{~s}$ clearly alters the nitric oxide output in exhaled air. This, in part, may be explained by the increased diffusing capacity for nitric oxide (TLNO) which is seen at the increased lung volume at TLC. ${ }^{12}$ Increased TLNO at TLC may also explain the lowest value for FENO on maximal exhalation compared with spontaneous breathing (table).

It is therefore possible to measure endogenously produced nitric oxide in man from exhaled air. Strong circumstantial experimental evidence ${ }^{1011}$ leads us to infer that it is derived from pulmonary endothelium at a similar site in the lungs to the evolution of carbon dioxide-that is, close to and including alveoli. The measurement from mixed expired air collected over five minutes of tidal breathing is more reproducible than from a single breath test which may be affected by enhanced TLNO at TLC. These measurements of exhaled nitric oxide may have particular importance in clinical practice in such disorders as hypoxic chronic obstructive lung disease where there is evidence of impaired pulmonary endothelial production of nitric oxide. ${ }^{4}$

1 Moncada S, Palmer RMJ, Higgs EA. Nitric oxide: physiology, pathophysiology and pharmacology. Pharmacol Rev 1991;43:109-42.

2 Palmer RMJ, Ferrige AG, Moncada S. Nitric oxide release accounts for the biological activity of endothelium-derived relaxing factor. Nature (Lond) 1987;327: 524-6.

3 Archer SL, Tobins JP, Raij L, Weir EK. Hypoxic pulmonary vasoconstriction is enhanced by inhibition of the synthesis of an endothelium derived relaxing factor. Biochem Biophys Res Commun 1989;164:1198-205.

4 Dinh-Xuan AT, Higenbottam TW, Clelland CA, PepkeZaba J, Cremona G, Butt AY, et al. Impairment of endothelium-dependent pulmonary artery relaxation in chronic obstructive lung disease. $N$ Engl f Med 1991; 324:1539-47.

5 Pepke-Zaba J, Higenbottam TW, Dinh-Xuan AT, Stone $\mathrm{D}$, Wallwork J. Inhaled nitric oxide as a cause of selective pulmonary vasodilatation in pulmonary hypertension. Lancet 1991;338:1173-4.

6 Pulmonary microstructure. In Williams PL, Warwick R eds. Gray's anatomy. Edinburgh, London, Melbourn and New York: Churchill Livingstone, 1980:1260.

7 Palmer RMJ, Ashton DD, Moncada S. Vascular endothelial cells synthesize nitric oxide from L-arginine. Nature (Lond) 1988;333:664-6.

8 Borland CDR, Higenbottam TW. A simultaneous single breath measurement of pulmonary diffusing capacity with nitric oxide and carbon monoxide. Eur Respir $f$ 1989;2:56-63.

9 Stavert DM, Lehnert BE. Nitric oxide and nitrogen dioxide as inducers of acute pulmonary injury when inhaled at relatively high concentrations for brief periods. Inhalat Toxicol 1990;2:53-67.

10 Gustafason LE, Leone AM, Persson MG, Wekland NP, Moncada S. Endogenous nitric oxide is present in the exhaled air of rabbits, guinea pigs and humans. Biochem Biophys Res Comm 1991;181:852-7.

11. Cremona G, Takao M, Higenbottam TW. Differences in exhaled NO between intact pigs and isolated lungs perfused with Krebs dextran albumin. Am Rev Respir Dis 1993;147:A226.

12 Sharma VS, Taylor TG, Gardiner R. Reaction of nitric oxide with haem proteins and model compounds of haemoglobin. Biochemistry 1987;26:3837-43.

13 Bassenge E, Busse R, Pohl U. Abluminal release and asymmetrical response of the rabbit arterial wall to endothelium-derived relaxing factor. Circ Res 1987; 61(Suppl 11):1168-73. 